Dossier : Literaturas y disidencias sexuales

\title{
Identidad y disidencia sexual en el rap feminista queer: un análisis narratológico de "Lisístrata", de Gata Cattana
}

Critical analysis of feminist identity in the song "Lisistrata" by the feminist rapper Gata Cattana

Susana Pinilla Alba

DOI: https://doi.org/10.24215/25457284e118

Bergische Universität Wuppertal, Alemania

susanapinillaa@gmail.com

Recepción: 20 Noviembre 2019

Aprobación: 03 Julio 2020

\section{Resumen:}

El presente artículo es un análisis microdiscursivo de la canción "Lisístrata" de la rapera española Gata Cattana (1991-2017). Se emplea una metodología procedente de los Estudios Críticos del Discurso, la teoría de la interseccionalidad y la narratología feminista y queer de S. Lanser. Se tienen en cuenta las dimensiones macro y microdiscursivas, así como el análisis de la voz comunal, autorial y queer. Por una parte, se busca desentrañar las implicaciones sociales que esta enunciación disidente trae aparejada en la construcción identitaria de la propia autora y el público al que interpela. Por otra, se pretende describir y analizar el aporte de Gata Cattana para resignificar el rap español.

Palabras ClaVe: Rap feminista, Gata Cattana, Narratología feminista, Estudios Críticos del discurso.

\section{Abstract:}

This article is a microdiscursive analysis of the song "Lisístrata" by the Spanish rapper Gata Cattana (1991-2017). It uses a methodology from Critical Discourse Studies, the theory of intersectionality and S. Lanser's feminist and queer narratology. Macro and microdiscursive dimensions are taken into account, as well as the analysis of communal, authorial and queer voice. On the one hand, it seeks to unravel the social implications that this dissident enunciation brings with it in the identity construction of the author herself and the public to which she appeals. On the other hand, the aim is to describe and analyse Gata Cattana's contribution to re-signifying Spanish rap.

KEYWORDS: Feminist rap, Gata Cattana, Feminist narratology, Critical Discourse Analysis.

\section{INTRODUCCIÓN}

Gata Cattana es el nombre artístico que Ana Isabel García Llorente (1991-2017) utilizaba en su faceta de rapera. Esta polifacética artista se consideraba a sí misma rapera y poeta. En el rap se materializa un alter ego político y hardcore, y en la poesía aflora su yo más sentimental. La tematización de lo social es recurrente en toda su producción, en la que destacan sobre todo referencias anticapitalistas, republicanas y feministas. Su rap resignifica la escena de hip hop nacional mediante un simbolismo retórico, que se percibe en el uso funcional del lenguaje y en las referencias culturales procedentes de la historia antigua, la filosofía, la mitología y la actualidad política; pero que no renuncia a la autenticidad expresada mediante la jerga juvenil, el habla popular y la dicción con acento andaluz. Es por ello que su peculiar manera de rapear abre nuevos horizontes en un panorama dominado por el rap mainstream, heredero en aspectos formales y conceptuales del "rap de la vieja escuela" estadounidense.

La canción "Lisístrata" (2015) nace como un manifiesto feminista para sintetizar y complementar un trabajo anterior, "Tributo I" (2014). Es por ello que muchos consideran "Lisístrata” como el "Tributo II", oda a las mujeres ilustres y protesta contra el patriarcado y el fanatismo religioso. Pese a las semejanzas que se establecen en estas dos canciones, la fama que ha acumulado Lisístrata la convierten hoy en día en un himno del feminismo periférico, utilizado como propaganda por el pueblo que se subleva contra la falta de libertad que el sector más retrógrado de la derecha y la Iglesia pretenden instaurar. 
En este artículo me ceñiré al análisis de "Lisístrata”, cuarta pista del EP Anclas (2015), producido por Wiloo en La Cucaracha estudios. Destaca el empleo del sampleado y el scratch por parte de su DJ y amigo Carlos Esteso. Esta maqueta surge posteriormente a su primer EP Los siente contra Tebas (2013).

En Anclas asistimos a un intento de poetización formal del rap, visible en el tono culturalista de este trabajo, capaz de combinar referencias del propio mundo del hip hop con personajes ilustres del pasado y presente. Los temas que aparecen en las canciones de este trabajo serán retomados en "Lisístrata", junto con la impronta feminista que convierte a esta canción en un himno imprescindible en el rap feminista. La provocación y la desobediencia civil como medio de expresión de una voz silenciada son el leitmotiv de la maqueta. Por eso, al igual que en "Lisístrata", encontramos en este disco referencias al empoderamiento que la mujer lograría teniendo una voz y dibujando un espacio propio para proyectar sus reivindicaciones. La toma del espacio del rap, tanto estética como material, supone un acto político de rebeldía, como observamos en estos pasajes: "Guerra abierta y propaganda en cada uno de los flancos", "Los puñales" o "Tengo lengua, no hablen por mí" (Cattana, 2015). La necesidad de luchar unidas es otro tema recurrente del disco, que en "Lisístrata” será central: "Quiero el clamor de la plebe, una catana afilá pa' los reyes” (Cattana, 2015).

La autora hace acopio de un amplio aparato cultural y popular que expresa a través de anécdotas, referencias culturales o maneras de hablar de gran poder ilustrativo. En primer lugar, desarrolla la necesidad de reeducar a la población para erradicar la violencia machista. Esta formación es posible mediante el consumo de un rap feminista y el recuerdo colectivo de las mujeres olvidadas. En segundo lugar, se expondrá la tesis de la función social del rap feminista del margen, en la corriente hardcore y conciencia que representaba la artista, como instrumento que empodera a la mujer y como puente para tomar la esfera pública y reivindicarse.

\section{Metodología para el anÁlisis del manifiesto feminista “Lisístrata”}

Para el análisis de "Lisítrata" entra en consideración una metodología integral capaz de responder a las cuestiones que me propongo con este análisis: estudiar las implicaciones narratológicas y políticas de la canción, tanto a nivel interno como contextual. Para ello, me resulta un marco metodológico apropiado aquel procedente de los Estudios Críticos del Discurso (Van Dijk, 2011), en tanto que el discurso híbrido del rap, difícilmente clasificable según la tipología discursiva, se presta a ser analizado mediante los mecanismos que se aplican en el discurso político. Razones para ello son sus características formales, en lo que respecta a la argumentación de carácter persuasivo y a la disposición de sus partes, análoga a la retórica clásica. Otro factor que sitúa a "Lisístrata" como un manifiesto feminista lo encontramos en la procedencia de los dos pasajes que reproducen las palabras que pronunció la asambleísta Rosana Alvarado el 12 de julio de 2012 contra la penalización del aborto en Ecuador. ${ }^{1}$ Ambos interludios funcionan como refuerzo de la argumentación central de la canción.

El Estudio Crítico del Discurso (ECD) se centra en un discurso político del odio para desmontarlo y exponer abiertamente las estrategias de dominación, que delimitan las relaciones de poder alimentando la violencia y opresión (Pardo, 2012). No obstante, en el rap disponemos ya de una deconstrucción de dichos discursos de represión, de modo que en el análisis nos centraremos en la forma en la que Gata Cattana desarticula estos discursos situando como incitadores de la opresión al fanatismo religioso y al sistema de comportamientos, valores e ideas que promueve la sociedad patriarcal. Son dos las dimensiones que esta estructura propone. Por una parte, un plano micro-textual basado en el análisis pormenorizado de la canción, es decir, su forma y contenido, desde un enfoque narratológico feminista y queer que indague en la construcción y función de las categorías narrativas en el rap, por su analogía con la literatura; y otro nivel macro-textual, que se ocupe de la relación que dicha carga semántica comparte con el momento y lugar en el que se está interpretando la canción (Pardo, 2012). Con este propósito resultan relevantes estudios que exploran estos aspectos situacionales en la construcción identitaria. Destacan los aportes de la sociología de la música (Vila, 1996 y Frith, 2001) en su afán por delimitar cómo los nexos entre sonido, texto e interpretación 
interpelan a unas identidades y no a otras, marcadas por distintas intersecciones (etnia, clase y género), y cómo dichos constructos categoriales se retroalimentan de los significados que les confieren los oyentes.

A fin de mostrar las implicaciones político-sociales que la canción desempeña en la actualidad se hace necesario integrar ambos niveles en un análisis discursivo que pretenda explicar cómo están dispuestos los aspectos artísticos que cohesionan el texto de Gata Cattana (los elementos narratológicos y estilísticos) en relación con la reivindicación feminista, cuya proyección es visible en la impronta que ha dejado su trabajo en la recepción.

El análisis detallado del narrador en el rap permite construir nuevas categorías para la narratología feminista. Estas relaciones entre el narrador y el narratario resultan más comprensibles entendiéndolas bajo el prisma que ofrece la teoría de la interseccionalidad (Collins, 2019). Al posicionamiento per se del hip hop feminista y queer con las categorías tradicionalmente estigmatizadas por razón de género, clase y etnia habría que sumarle el rasgo esencial de este estilo: ser la voz de los jóvenes. Estudiar cómo el alter ego de la autora dialoga con las generaciones y colectivos a los que interpela, ofrecería aportaciones significativas en el nivel macrotextual. Gata Cattana no está enunciando desde su idiosincrasia personal, sino que traza una reivindicación que entrecruza varias categorías para servir como puente para que otras subalternas puedan ser oídas (Spivak, 1993). Su rap tiene una proyección global porque es un grito contra el capitalismo, el machismo, el imperialismo y el paternalismo, articulado mediante un estilo musical que retoma el descontento de un colectivo con rasgos identitarios concretos. Así pues, esta canción recoge la voz de un sujeto discriminado que se erige como portavoz de una identidad con rasgos de clase, de género, generacionales y étnicos similares.

El texto que nos ocupa, como se señaló más arriba, podría considerarse como un discurso político. De acuerdo a la retórica clásica, podríamos estructurarlo en las siguientes secuencias: exordio, en el que la autora se presenta y simpatiza con el público; narratio, en la que expone y argumenta su tesis; y peroratio, en la que logra el convencimiento del auditorio. A su vez, debido a las necesidades musicales de la canción, se han intercalado dos interludios, que funcionan en el primer caso como nexo y en el segundo como reafirmación y síntesis de la peroratio. Son evidentes las implicaciones políticas de esta canción: la mayoría de ellas aparecen diseminadas en la narratio, que se extiende hasta el final del último estribillo.

\section{IMPLiCACiONES SOCiOPOLÍTiCAS DEL uSo DE LA VOZ EN "Lisístrata", de Gata CATTANA}

Según la narratología feminista de Susan Lanser (1992), las voces que las mujeres han empleado en su obra han sido fundamentalmente tres: la autorial, la personal y la comunal. En la canción "Lisístrata" distingo dos voces: la autorial en el plano intra y extradiegético y la comunal, mediante la enunciación en primera persona, tanto en plural como en singular. No considero que la voz personal esté presente en esta canción, ya que el uso del narrador autodiegético comparte más rasgos con el propósito de expresión identitaria de un grupo que con el de narración de los asuntos individuales. Trabajos posteriores de Lanser $(2015,2018)$ darán un giro más interseccional y queer a su obra. La metodología que se propone para el análisis de este manifiesto pretende abordar el análisis crítico del discurso mediante un enfoque narratológico desde la resistencia, fiel al concepto de feminismo que la propia autora fomenta y difunde en esta canción. A continuación, trataré las implicaciones estéticas y políticas que estas dos voces articulan en el texto que nos ocupa, mediante el análisis de los pasajes de la letra de la canción.

\subsection{Voz comunal-queer: resignificación de un constructo social y estético}

Al conjunto de narradores que hablan en nombre de una comunidad Lanser los denomina voz comunal, concepto que define así: "a sprectrum of practices that articulate either a collective voice or a collective of 
voices that share narrative authority" (1992, p. 21). Esta voz se proyecta con distintos enfoques: de forma singular, como un narrador que enuncia como portavoz de un colectivo; de forma simultánea, como una colectividad representada con un narrador plural; o bien, como un narrador secuencial, compuesto de varios narradores que se expresan por una misma causa en secuencias discursivas distintas. Podríamos encontrar la presencia de estos tres tipos en "Lisístrata".

La existencia de una voz grupal se pone de manifiesto en la presencia del feminismo interseccional y periférico que se enuncia mediante los siguientes recursos. Por una parte, el ámbito del hip hop es un potencial escenario para la cosificación y humillación de la mujer. La rapera, en tanto que enuncia, toma el poder para reivindicar todo aquello que le preocupa. Cuando habla no solo construye feminismo, sino que está reinventando el género, deconstruyendo sus rasgos "esenciales". Ofrece una óptica comunal, diferente del rap conciencia que producen los hombres, quienes fomentan en general el individualismo y la competencia. El rap feminista de Gata Cattana no es la expresión de un ego exaltado, característico del rap mainstream, sino un llamamiento a la sororidad. De ahí que, en numerosas ocasiones, aluda a referentes de mujeres de lugares y épocas distantes, con problemáticas ajenas a la realidad europea, como es el caso de los interludios de esta canción o su apelación al narratario en otros trabajos suyos: "Para mis gatas, para mis negras, pa' mi' mulata" [...] (Cattana, 2017). Este propósito de hermanamiento y apoyo a las mujeres que sufren discriminación tiene un calado interseccional, pues el posicionamiento de la rapera europea y blanca que es Gata Cattana con sus compañeras de otros continentes e idiosincrasias permite ofrecer un feminismo no hegemónico que rompe con el discurso feminista que la primera oleada traía aparejado, como se expondrá más adelante.

Por ello, el marco que el narrador comunal encuentra en el rap para mostrar su descontento y vindicaciones es el de la resistencia, el de la sublevación contra un régimen dominante en el que la mujer no logra representación legítima. Por ello, podemos considerar la voz comunal como un narrador queer en el tercer significado que Lanser ofrece en su tipología del narrador queer: "a voice that confounds the rules of voice itself and thus baffles our categorical assumptions about narrators and narrative" (2018, p. 926), cuya función en la canción es paralela a la enunciación en primera persona, ya sea singular o plural, para invalidar el discurso del odio. Esta deconstrucción opera con el propósito de resignificar el rap en dos direcciones: la conquista del cronotopo negado a la mujer, simbolizado en la ciudad y la noche; y el cuestionamiento del rol tradicional de la mujer en sociedad y en el mundo del hip hop.

\subsubsection{Resignificación del rap: rap feminista andaluz contra la desigualdad}

Al principio de la canción, ya asistimos mediante la voz singular a dos concepciones opuestas de mujer sobre las que Gata Cattana toma partido en "Lisístrata": "Yo no camelo perfumes de Nina Ricci / Soy más de libros de la Silvia Federici” (Cattana, 2015). Se establece un posicionamiento político e intelectual determinado, es decir, la rapera se presenta como perteneciente a un feminismo marxista, el que defendía Silvia Federici ${ }^{2}$ y no como una consumidora de perfumes de moda, los patrocinados por la empresa Nina Ricci. ${ }^{3}$ La autora cita esta marca como ejemplo del poder que tienen estas empresas para incidir en el imaginario colectivo al imponer un prototipo de belleza. Así pues, en el anuncio aparece una mujer joven y bella avanzando vestida de princesa hacia un montículo de manzanas para tomar el fruto del árbol que resulta ser el perfume. La contraposición que Gata hace de estos dos modelos de mujer y su posicionamiento con el feminismo, al que se accede leyendo, indican la procedencia intelectual de la autora y su desacuerdo con la construcción de una feminidad superficial y prototípica, basada en el canon de belleza actual, que la misma marca denomina así: "Una búsqueda de la feminidad traviesa y tan tentadora como la fruta prohibida. Una mujer en plena expansión” (Puig, 2019).

Esta imagen de "mujer florero" difiere de la mujer con la que Gata se identifica: 


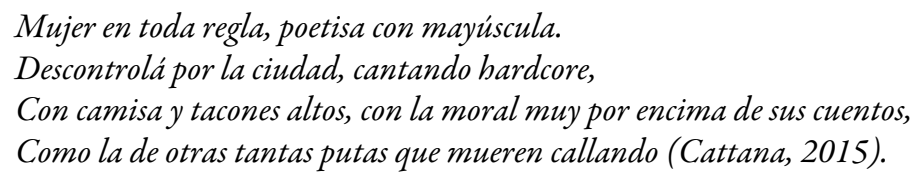

Los siguientes versos actúan como una suerte de personificación de la mujer del rap feminista, la que ella es por voluntad propia y por oposición a la educación patriarcal que ha recibido "con la moral muy por encima de sus cuentos" (Cattana, 2015). Dichos cuentos pueden entenderse como todo el acopio cultural procedente de las costumbres, la religión y las ideas que construyen la visión de mujer sumisa con la que se educa a las niñas en casi todas las civilizaciones de todas las épocas históricas. La mujer con la que Gata se identifica es con una intelectual (con camisa), que no niega su femineidad pese a estar haciendo rap (con tacones altos) y que otorga una cualidad literaria (poetisa con mayúscula) al acto performativo del rap (cantando hardcore). ${ }^{4}$ Este segundo verso introduce tres elementos que acercan a la autora al rap hardcore: "descontrolá" indica el modo "punky" con el que hablaba de su rap, la ciudad introduce el espacio urbano por excelencia en la cultura hip hop y el hardcore muestra que este estilo vital tiene un reflejo en su música, en este caso el rap. El hecho de que se pasee por las calles con esa indumentaria, sin miedo, desafiando los dogmas patriarcales recibidos, se contrapone al destino que muchas otras mujeres no pueden evitar. Por eso, incita a la desobediencia frente a la idea que se inculca a las niñas acerca de salir con miedo al ámbito público, es decir, el terror que la mujer experimenta en los cuentos infantiles o mediante las figuras demonizadas con las que se asusta a los niños. Gata rompe con la idea de que la mujer debe permanecer en el ámbito privado: "Yo hago lo que quiero bajo el 'niña no andes sola"' (Cattana, 2015).

En estos dos versos se presenta el rap hardcore y su vinculación con el sujeto enunciador: "Haciendo make it rain a lo Hard Candy" y "Descontrolá por la ciudad, cantando hardcore" (2015). Analizando por separado estos pasajes, Gata Cattana articula dos mensajes apelando a dos narratarios distintos. Por una parte, expone la necesidad de desterrar a la mujer sumisa, referente mayoritario en nuestro patrimonio cultural, mediante una sacudida catártica a favor del compromiso político conjunto. Por otra parte, como autora de rap feminista, pretende resignificar el rap para lograr ser escuchada en un espacio en el que la voz de la mujer ha estado vetada. Se deduce por ello que el empleo de la voz comunal tiene implicaciones distintas en la recepción del mensaje. Por una parte, la propuesta dirigida a las mujeres se expresa a través de la singularidad del yo, que busca convertirse en adalid de la lucha feminista; y con ello, involucrar al narratario para que tome las calles, participando del poder, abandonando la otredad y valorándose como sujeto pensante y enunciador. Por otra parte, la deconstrucción de los pilares del rap tradicional misógino abarca un horizonte más amplio de recepción, que incluiría a "todos" los consumidores de este género musical.

Esta idea aparecerá reforzada en otros pasajes. En el primer verso ya asistimos a la representación de Gata Cattana como mujer libre, lo que nos recuerda al estilo vital punk mencionado en la canción unos versos más arriba: "Haciendo make it rain a lo Hard Candy, modus operandi, rayaos, estampa'os, rollo punky". (Cattana, 2015). Gata pretende con su obra hacer "make it rain" a lo Hard Candy ${ }^{6}$ una resignificación del rap y una perspectiva de estudio comprometida con la causa feminista, una causa que ella entiende desde el feminismo queer que promueven autores como Despentes o Preciado. ${ }^{7}$ Se concibe la expresión "make it rain" como hacer hardcore rap, con un estilo Hard Candy, que podría interpretarse como una inversión de roles, en el que la mujer ejerce el poder y el sujeto abusador depende de su benevolencia. Esto evidencia que su rap no abusa del cuerpo de la mujer como en el videoclip de Fat Joe, sino que castiga al machista sin ningún tipo de miramiento, como el rol que representa Ellen Plage en la película Hard Candy. Las referencias “rayaos, estampa'os, rollo punky" sirven para intensificar la relación entre su rap activista con el feminismo de Despentes, cuya actitud vital conecta con el espíritu combativo proveniente del punk.

El verso anteriormente comentado será clave para conectar la imagen que Gata quiere proyectar sobre la mujer dueña de sí misma. Es decir, frente a la princesa delicada que arranca una manzana del árbol en la propaganda de Nina Ricci, Gata propone una mujer de la calle y de la noche (atributos vinculados con el rap) 
que canta con un espíritu combativo y activista contra la violencia patriarcal. Este rap hardcore se caracteriza por el cuestionamiento de las categorías que constituyen el propio género, repensándolas para dar cuenta de nociones desde las que las identidades discriminadas puedan proyectarse. En el tema antecesor de "Lisístrata" aparece abiertamente esta intención:

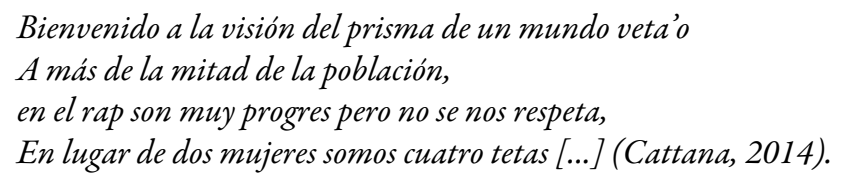

Gata Cattana apoya el desmantelamiento de este discurso opresor mediante la creación de nuevas formas enunciadoras que reflejen los lastres que impiden el progreso en todas sus dimensiones: el fanatismo religioso, las costumbres sin fundamento, etc. De la interpretación de su discurso se deduce que el rap tradicional, con una exacerbación de la masculinidad y una imposición maniquea del binarismo de género que cosifica a la mujer, no puede ser ningún instrumento de liberación.

Las mujeres que cantan rap expresan la voz de una mitad de la población cuyas ideas y formas de sentir han sido "vetadas" y el ámbito del hip hop no es excepcional: son pocas las raperas conocidas, pese a que ellas hacían rap a la vez que los hombres. La mención de Keny Arkana ${ }^{8}$ como máximo referente en el rap francés tiene a mi entender una clara correlación con la escena andaluza en España. Keny Arkana, como referente global, incita con su música a la desobediencia civil, pero también hace reivindicación del dialecto: "Marseille, Marseille, a toujours fait vibrer la France. Fut un temps où tout l'Hexagone rappait même avec l'accent" (Keny Arkana, 2011), así construye una identidad étnica, la de los hispanohablantes en la diáspora, pero también la de los propios marselleses, discriminados en su país, situación comparable a la marginación y prejuicios que reciben los andaluces en España.

\subsubsection{Resignificación del sujeto y receptor feminista}

Otra cuestión imprescindible para entender el enfoque queer e interseccional de la obra de Gata Cattana, aparece en la referencia bibliográfica que la propia rapera ofrece al oyente: la obra crítica La teoría King Kong (Despentes, 2006), ensayo del feminismo del margen, que tanto por temática como por enunciación podemos adscribir dentro de la teoría queer. La apelación a la necesidad de la lectura de este libro tiene un fin didáctico, ofrecer el material bibliográfico para educarse en feminismo, pero también reivindicativo, pues la consecución de la libertad de movimiento en espacios públicos no tiene por qué ser una lucha pacífica. Por eso la tesis de Gata "deja de poner impedimentos" puede ser entendida como un aviso. Esta libertad de movimientos de la que ella hace alarde en la estrofa previa al estribillo, pero que cuesta la vida a tantas mujeres "como la de otras tantas putas que mueren callando" (Cattana, 2013) es la tesis fundamental de Despentes en su teoría.

Esta intertextualidad presente en la canción hace converger las tesis de ambas autoras: la violencia solo es legítima en una sociedad patriarcal de modo unidireccional, del varón hacia la mujer. Por ello, según Despentes hay una construcción social que regula todos los ámbitos y hace que otro modo de ejecución violenta no solo sea penalizada, sino que resulte imposible. Su idea sobre la necesidad de acción se fundamenta en el adoctrinamiento que la mujer recibe desde que se construye su género antes del nacimiento como un entramado de normas, comportamientos y aspiraciones sociales que condicionan su respuesta ante situaciones traumáticas a favor del varón y no a favor de su propia integridad física y psicológica. Por eso, en esta misma estrofa se tematiza la violencia sexual y el acoso callejero: "deja de follarme con los ojos ya de paso/ cuando paso por la calle sola en todo momento" (Cattana, 2015). Este mismo tema aparece más desarrollado en el antecesor de esta canción "Tributo I", al principio de la misma: 


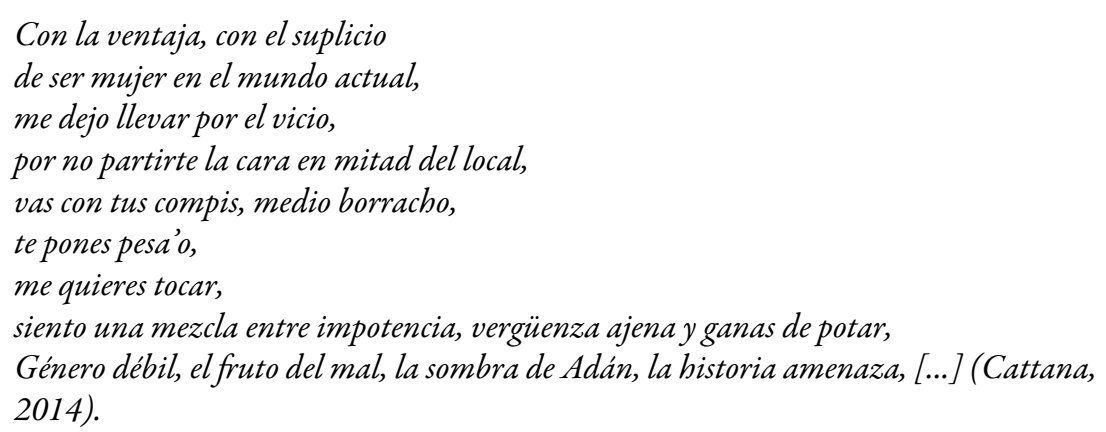

En este pasaje se describe la lucha psicológica que la mujer debate consigo misma para no responder violentamente al acoso del que es presa cuando sale del ámbito privado. Es un intento de hacerle recordar que ese espacio no le pertenece y, por tanto, lo que le ocurra en él es su responsabilidad, su castigo por la desobediencia. Las emociones, principalmente "la impotencia", vienen marcadas por la carga mental fruto de la educación patriarcal: las expresiones "género débil" hacen referencia a la incapacidad de defensa física, que le hace recordar a la mujer que en un combate cuerpo a cuerpo tiene las de perder; "fruto del mal" se asocia con la culpa que la mujer debe sentir por ser seductora, por provocar deseo sexual en el varón; "sombra de Adán" construye la identidad femenina en torno a la mediocridad, como mitad sin completar, reducto imperfecto de otro ser superior. Por último, "la historia amenaza" podría interpretarse como los referentes femeninos de la historia que fueron asesinados de las formas más terribles imaginables cuando se rebelaron. La historia que han construido los hombres se ha encargado de que la mujer sea consciente de dos cuestiones: hay pocas mujeres que puedan trascender y las que se han salido del rol asignado han sufrido martirio.

Este tema será retomado en la enumeración final con todas las formas de violencia que se han aplicado a las mujeres en todos los países y momentos de la historia. El empleo del recurso de la ironía, para mostrar sin tapujos un estado de horror absoluto, permite que los hechos hablen por sí solos: "Lapídame, humíllame, si quieres ponme un burka, arráncame la voz y el clítoris pa' ser más pulcra” (Cattana, 2015). Son referencias a distintas formas de tortura que se aplican a las mujeres estrictamente por su condición de mujer y todas tienen como objetivo el recuerdo de la inferioridad de la mujer y la obediencia al hombre. La ablación del clítoris asegura la virginidad y el sufrimiento en todas las facetas que conecta a la mujer con su sexo: menstruación, relaciones sexuales, parto. La lapidación asegura la servidumbre doméstica y sexual, exclusivamente al marido, en este sentido, al amo. La humillación y el silenciamiento hacen referencia a otras formas de opresión, las que coexisten en la sociedad occidental en la que las formas explícitas de violencia hacia la mujer no están tan normalizadas. En este sentido, dichas formas de violencia se materializan en el sufrimiento silenciado de las mujeres en el ámbito privado, en sus puestos de trabajo, en el ámbito escolar, universitario y político, entre otros. Pero también en los espacios que en teoría no les corresponden: la calle, la noche o los altos cargos. Son todas las manifestaciones de violencia que pese a no tener consecuencias físicas se subestiman. La voz comunal toma presencia en este sentido como la vulnerabilidad de todas aquellas mujeres que caminan por la calle solas frente al colectivo masculino, que se protege y actúa en conjunto: "vas con tus compis, medio borracho" (Cattana, 2014).

El estribillo que aparece a continuación culmina con la enumeración de mujeres ejemplares para el feminismo. Por ello, su cierre "sin más que decir que aportar a la causa" indica los muchos nombres de mujeres que desde diferentes ámbitos han contribuido o contribuyen al feminismo interseccional. La perífrasis de continuidad "ando cayendo ya, encallándome (endureciéndome)" indican que la lucha continúa en proceso, esa es su guerra civil personal, que a su vez es comunal, guerra entre hombres y mujeres de una misma patria. La referencia cultural que da nombre a esta canción, "Lisístrata", es símbolo universal de la lucha femenina para influir en las decisiones de los hombres y alude a la protagonista de Lisístrata (411 a.C.), comedia de Aristófanes. Pese a la interpretación que se pueda hacer de la comedia, que actualmente no podría ser considerada feminista, y salvando las distancias, podemos entender esta referencia cultural como símbolo del 
poder en manos de las mujeres (pues en la comedia tomaron la acrópolis) y la consecución de bienes sociales mediante la reivindicación que la mujer merece.

El verso "como la de otras tantas putas que mueren callando" (Cattana, 2015) tendría a mi entender varias lecturas. Por una parte, se refiere a las mujeres que realmente han muerto silenciadas, o cuyas muertes no han sido debidamente investigadas u honradas, o sea, todas esas mujeres subalternas que no le importan a nadie. Pero también podríamos entender este verso como todas aquellas mujeres que han aportado a la causa feminista, que han sido asesinadas o han desaparecido de la memoria colectiva. Teniendo en cuenta la presencia de una enumeración de mujeres con esas características tras el estribillo, me atrevería a afirmar que esta es la interpretación más acertada. Esta intención es común en gran parte de la producción feminista de rap a uno y otro lado del océano Atlántico. Destaca principalmente la canción "Las que faltaron" del grupo catalán Mafalda y la rapera feminista guatemalteca Rebeca Lane:

Siempre faltó la mitad, miro atrás y no están. Las que estaban siempre a un lado, las que siempre faltarán. Mujeres que hicieron historia, mujeres murieron sin gloria, ¿buscas referentes en libros? En la escuela no tienen memoria (Mafalda y Rebeca Lane, 2018).

La noción de memoria como reducto de un pasado glorioso reprimido es una constante en el rap feminista hispano. La estrofa inicial de "Lisístrata", que coincide con el exordio, se cierra con una captatio benevolentiae, en la que reconocemos la apelación directa al narratario, es decir, a los oyentes del siglo XXI. La introducción de la segunda persona, contrapone las dos identidades: opresores y oprimidos. Las beneficiarias del discurso, las bitches, podrían aliarse si toman en serio su mensaje, como vemos en: "Será mejor que trates mejor a esas bitches / No sea que de repente me escuchen y se compinchen". ${ }^{10}$ El uso de la jerga del rap femenino introduce aspectos lingüísticos y conceptuales que sirven para la creación de categorías en el rap femenino (Martínez, 2011), que muestran correlación con otras categorías femeninas que la teoría queer ha explorado (Halberstam, 1998). Aquí Gata Cattana emplea el vocablo con connotaciones jergales para referirse a una mujer excluida del sistema, una subalterna.

Podemos establecer una relación entre putas/bitches como ejemplo ilustrativo del uso de la jerga para aglutinar a una comunidad. Martínez (2011) considera tanto a la jerga como al sociolecto una medida de diferenciación, de integración, de liberación y de estigmatización. El empleo de esta terminología para referirse a las mujeres subalternas conlleva un claro sentido de "territorialización", pues al inscribirse como las otras en una sociedad que las margina, se cumple un propósito de diferenciación. Por otra parte, no hay que olvidar la resignificación del término "puta" que el feminismo interseccional y queer reivindica. Así pues, deberíamos entender la jerga de "Lisístrata" con una intención de "mantener y reforzar una imagen positiva de ellas mismas, al menos dentro de su grupo [...] ya que todo grupo puede ser desacreditado y todo grupo precisa mantener y defender su posición social, su prestigio y su autoridad, cuando esta pueda verse amenazada" (Martínez, 2011, p. 37).

Ante eso ofrece una reconversión de la historia, es decir, pretende narrar una historia alternativa, mediante el recuerdo de las mujeres olvidadas que impulsaron la causa feminista. Este apartado recoge la tesis que se explicita en el estribillo: una oda a sus compañeras, "un tributo a mis musas, que luchan" (Cattana, 2015) y una alianza para acabar con la discriminación: "yo os invoco, hijas de Eva, buscando una luz" (2015). La invocación funciona como una apelación a las mujeres caídas representadas en la enumeración anterior, que denomina "hijas de Eva", que se hallan "buscando una luz", lo que tiene connotaciones con un anhelo de esperanza en un cambio. Esto es lo que se deduce de los dos finales del estribillo que expone la artista: "un tributo a mis musas, que luchan” y "yo os invoco, hijas de Eva” (2015). Puesto que las dos acciones están en presente sobreentendemos que dichas "musas" siguen luchando, pero el significado léxico de "invocar" nos hace pensar en las mujeres del pasado, a las que llama "hijas de Eva", cuya carga semántica aparece explícita en los interludios que en el apartado posterior serán analizados. 
La última referencia del rap feminista como vía para liberar a las mujeres la encontramos en el siguiente verso de la estrofa previa al estribillo final: "imbéciles se creen que son la élite, caerán, por su propio peso cuando rescate a Eurídice"11 (Cattana, 2015). Gata se presenta como la salvadora de Eurídice mediante el verbo en primera persona, pero esta enunciación puede interpretarse como portavoz de la comunidad. Teniendo en cuenta el mito, el salvador de Eurídice es un hombre, Orfeo, famoso por sus cualidades musicales y poéticas. Gata se posiciona al mismo nivel que Orfeo, porque solo él, por sus capacidades cognitivas y por su amor por Eurídice, puede llevar a cabo esta empresa. Si Eurídice fuera la metáfora de las mujeres desvalidas víctimas del patriarcado, algo que parece posible por el papel pasivo de la ninfa en este mito, podríamos interpretar que la rapera feminista, en tanto que combina música y poesía con esta intención filantrópica hacia las mujeres, es capaz de liberarlas. A su vez, esta liberación de la mujer, representada en el público que la escucha y por el que ella canta destronará a los hombres que utilizan sus privilegios para oprimir: "imbéciles, se creen que son la élite, caerán” (2015). Dicha élite social se compone de aquellos que gozan de privilegios, en este sentido, por cuestiones de género y clase. La interpretación de la expresión "caer por su propio peso" nos indica un sentido de justicia: la balanza se inclinará hacia la justicia, porque cuando la mujer se alíe al feminismo, los hombres no tendrán más remedio que adoptar nuevos roles y, por ello, su caída será una consecuencia inexorable del avance de esta lucha.

\subsection{La voz autorial: deconstrucción de un discurso del odio.}

En este apartado me gustaría analizar el narrador heterodiegético que aparece en Lisístrata para desentrañar las funciones que el uso de la voz autorial, empleando la terminología de Lanser (1992), desempeña para la creación del marco espacio-temporal que justifica la dominación. Así pues, la proyección de esta canción se centra en la educación en feminismo del pueblo, de ahí que la relación del narrador (trasunto de la autora) y el narratario (auditorio del siglo XXI) tenga implicaciones claras en la materialización de este fin. El rap conciencia feminista no pretende quedarse en el marco de lo estético, sino que ansía una reconversión y resignificación radical del statu quo. Esta voz aparece definida como "extradiegetic, and public, directed to a narratee who is analogous to a reading audience” (Lanser, 1992, p. 16). Por tanto, en el plano extradiegético este tipo de enunciación va a servir como argumentación en refuerzo de la necesidad de educación en feminismo y la resignificación del concepto mujer desde los derechos humanos y no desde su papel en la tradición y en la religión; y en el intradiegético tendrá como objetivo delimitar el cronotopo que sitúe la acción temática y diacrónicamente.

\subsubsection{Voz autorial extradiegética: los interludios}

Lanser denomina actos extrarepresentacionales a la inserción de generalizaciones o comentarios ajenos a la historia en el universo diegético. Este modo de narrar encuentra en el rap su correlato mediante el empleo de la técnica del sampleado, entendiendo esta como la inserción de fragmentos procedentes de distintos formatos: películas, publicidad, discursos de prensa, literatura, radio, etc. En "Lisístrata" encontramos dos interludios pronunciados por una misma voz en off, que corresponden al discurso político de la asambleísta feminista Rosana Alvarado. En la canción, sin embargo, se ambicionan los siguientes propósitos: ofrecer un ejemplo actual de misoginia que señale como culpable directo a la religión; denunciar el aparato social que permite la pervivencia del fanatismo y su poder ejecutivo; y la necesidad de expresar la lucha feminista mediante un formato transversal e interdisciplinario, en el que arte y política se retroalimenten.

El primer interludio procede de un pasaje de la Biblia que Alvarado emplea para argumentar los anquilosados dogmas que aún controlan las leyes de su país y la necesidad de legislar desde una constitución que considere a las mujeres personas y no pertenencias del varón. Para ello cita pasajes bíblicos en los que se 
sustenta la constitución ecuatoriana, como el que se recoge en el primero, cuya procedencia data de la obra de un padre de la Iglesia, Tertuliano:

¿Y no sabes tú que eres una Eva? La sentencia de Dios sobre este sexo tuyo vive en esta era: la culpa debe necesariamente vivir también. Tú eres la puerta del demonio; eres la que quebró el sello de aquel árbol prohibido; eres la primera desertora de la ley divina; eres la que convenció a aquél a quien el diablo no fue suficientemente valiente para atacar. Así de fácil destruiste la imagen de Dios, el hombre. A causa de tu deserción, incluso el Hijo de Dios tuvo que morir (Tertuliano, s.f.).

Esta imagen de la Eva bíblica, raíz de todos los males del hombre según la Iglesia, entronca con la alusión a Pandora (portadora de los males que asolarían a la humanidad, según la mitología clásica) que observamos tras la mención del mito de Prometeo en la última estrofa de la canción. A su vez, esta imagen de Eva actúa como introducción de la "mujer maligna" que se discute en las dos estrofas posteriores. Dicha visión será de nuevo retomada en el interludio final para desmontar las referencias bíblicas sobre la mujer:

Entiendo que la mujer, si no es prostituta, es tonta. Pero si no es ninguna de las dos, lo que sí está seguro es que es mala. Las mujeres no somos ni malévolas, ni malignas, no engendramos al demonio ni tampoco somos santas o que nos santificamos cuando llegamos a ser madres. Las mujeres somos mujeres (Cattana, 2015).

De este modo, la visión maniquea de la mujer procedente del imaginario colectivo fruto de la estructura ontológica patriarcal, ofrece dos posturas negativas, como criatura sumisa y "ángel del hogar”, de escasa potencialidad intelectual, o bien, como ente manipulador y peligroso para el hombre.

A fin de desterrar esa dicotomía (ángel-demonio), el rap feminista emplea al narrador autorial, como un contrapunto que refuerce la imagen de la mujer como un humano, incluso aquellas que son vulnerables a la discriminación por su ascendencia, raza, aspecto u orientación sexual; pero también con un fin explicativo que ofrezca en un plano macrodiscursivo un contexto en el que dicha discriminación se sigue produciendo y que no solo abarca tradiciones del pasado, sino que está aún hoy en día presente en nuestra misma sociedad.

\subsubsection{La voz autorial intradiegética en su construcción del cronotopo}

Las implicaciones que la voz autorial (trasunto de la autora) poseen a nivel intradiegético podemos observarlas en los siguientes versos, que a su vez siguen al primer interludio. Así pues, se trata de una contraargumentación de esa imagen de mujer, personificación del pecado y perdición del hombre. Esa imagen de mujer utilizada por la Iglesia como justificación de los crímenes contra las mujeres durante la Inquisición fue el mismo pretexto con el que se desplazó el paganismo en las civilizaciones antiguas: “ $i$ Que venga Dios y lo vea! Como a Gea se la marginó, / Ardió en la hoguera con tres brujas durante la Inquisición” (Cattana, 2015). Así pues, la marginación de Gea ${ }^{12}$ es consecuencia de la imposición del cristianismo. Esa imagen femenina de primera potencia engendradora será suplantada por el concepto masculino de Dios, materializado en Cristo.

La imagen de Gea quemándose a causa de la religión cristiana establece también un paralelismo con la encarnación de esta diosa en las brujas, que sufren el mismo castigo y son hijas de Gea, o de Eva, mujeres que rechazaron el papel que la Iglesia les quiso imponer. Este mito clásico también nos hace pensar en la Pachamama, madre tierra celebrada aún hoy en día en muchos lugares de Latinoamérica. Así pues, Gata Cattana habla en clave europea de la suplantación de Gea, pero la elección del interludio marca un vínculo con sus hermanas latinoamericanas, que también vieron su mitología ${ }^{13}$ coartada por la instauración del cristianismo. Por ello, esa imagen de mujer tiene un correlato con la mujer sumisa que el marianismo impuso con la religión: en la colonización española de América en el siglo XV, pero también en la Reconquista española medieval.

Otro ejemplo del empleo de narrador autorial lo encontramos para la creación de cronotopo a partir de los personajes. El carácter omnisciente del narrador contribuye a la delimitación temporal marcada de manera diacrónica mediante el empleo de personajes históricos para argumentar la tesis de "que las cosas no han 
cambia'o demasia'o a día de hoy", es decir, la situación para la mujer apenas experimentó un avance en los ámbitos filosófico y literario "desde Nietzsche hasta Unamuno", en el biológico "de Aristóteles a Darwin" o en el político "desde Franco hasta Rajoy" (Cattana, 2015). Estos marcos temporales tienen una función temática, pero sobre todo la pretensión de mostrar la misoginia de estos autores y, por ende, la de estos lapsos espacio-temporales. La autora se asombra mediante este argumento estilístico de énfasis de que en nuestros días “itenga que venir la Ana a rebatir a Freud!" (2015), es decir, tenga que ser una simple ciudadana la que cuestione el psicoanálisis falocéntrico de Sigmund Freud, presente todavía como enfoque analítico de muchas disciplinas actualmente.

Los siguientes versos de esta estrofa vuelven a la realidad española, que a su vez es la que está presente en muchos países occidentales: la instauración de medidas para solventar la desigualdad, como la discriminación positiva ${ }^{14}$ comenzaron para frenar la segregación racial en EEUU, pero se extendieron a la concesión de determinados privilegios a otros grupos sociales, como las mujeres, minorías étnicas o individuos con diversidad funcional. En teoría, se trata de una medida para disminuir la discriminación que sufren determinados colectivos por convicciones retrógradas arraigadas en las estructuras sociales. Pese a que a priori estas medidas tienen una buena intención, Gata Cattana se posiciona en contra de ellas ${ }^{15}$ en tanto que su carácter ilusorio y su aplicación mediocre solo podrían agravar la situación para estos grupos, como señala la autora "alimentando el tópico (machista o tradicional de mujer débil)" (Cattana, 2015).

Los "festivales feministas contra la segregación” le parecen una pantomima que no tiene correlato en la realidad, porque no disminuye la discriminación real, sino que la acentúa y desacredita a las mujeres, ya que a ojos de la sociedad su puesto no se debe a su preparación o méritos sino a una ley que las ampara ciegamente. Gata Cattana argumenta en esta estrofa que es necesario endurecer las leyes sobre violencia machista y desterrar la imagen de mujer portadora del mal para brindar las mismas oportunidades a todos los individuos, pero no necesariamente se tienen que pactar unas cuotas o puestos destinados solo a mujeres, ya que eso solo sería una medida retórica para inflar de feminismo un discurso que no refleja la situación que viven las mujeres día a día. Siguiendo su argumentación, el feminismo no se logra mediante un cambio teórico legal, que "obligue" a gobiernos y empresas a incluir mujeres para que la prensa se haga eco y así limpiar su imagen pública, sino a una sacudida de la mentalidad, tradiciones y roles sociales. Una modificación que debe venir desde dentro hacia fuera y no viceversa. Lo que Gata Cattana plantea es que dichas medidas legales son necesarias, pero sin una convicción feminista estas pueden ser manipuladas, malentendidas y tergiversadas para potenciar la discriminación.

Por otra parte, esta función espacio-temporal sirve para deconstruir el discurso de dominación, en este caso, como crítica de la misoginia del paganismo. La referencia al mito de Prometeo, establece a nivel intradiegético relaciones entre un narrador-voz comunal y un narratario-varones de la Antigüedad clásica. Así pues, el mito de Prometeo contribuye igualmente a la creación de un cronotopo que explicaría la vulnerabilidad del poder, con la facilidad con la que desde el paganismo se explica la instauración de un régimen patriarcal: "Desde que Prometeo les mostró el truco del fuego / Sometieron nuestro ego desde Atenas a Estambul” (Cattana, 2015).

\section{Conclusiones}

La canción "Lisístrata" supone un referente feminista en el mundo hispánico al mismo nivel que otros himnos feministas de autoras más conocidas como: "Mujer lunar" de la guatemalteca Rebeca Lane o "Antipatriarca" de la chilena Ana Tijoux. Es muy representativo que esta canción se popularizara como un manifiesto feminista con recepción muy variopinta, tanto en España como en Hispanoamérica, pese a formar parte de una escena underground. Sorprende que Gata Cattana saltara a la fama en 2017, poco antes de que su primer LP Banzai (2017) estuviera completo, y fue solo a raíz de su fallecimiento cuando su persona y obra lograron mayor difusión, con la mitificación que arrastra una muerte inesperada y prematura. 
En este trabajo he querido demostrar en qué medida el rap feminista actúa como motor del cambio en el plano social y artístico. En un plano microdiscursivo se aprecia cómo a través del análisis del rap desde los ECD y la narratología feminista interseccional podemos visibilizar el trabajo que las raperas feministas están desarrollando en la deconstrucción de un discurso misógino. Así pues, los aspectos estéticos y políticos del rap feminista de Gata Cattana aparecen de modo ilustrativo en la canción "Lisístrata" y es por ello que la relevancia de esta obra de arte en el panorama del rap en español aumenta año tras año. De esta lectura se deducen importantes implicaciones para el feminismo: la necesidad de hermanamiento no parece posible sin un adalid de la lucha, sin un individuo levantado que sea capaz de tomar el poder y sublevarse. Este llamamiento o sacudida catártica puede ser llevada a cabo por el rap feminista hardcore, entendiendo esto como un rap conciencia político, un rap enunciado por un sujeto femenino que se plantea las fronteras de lo público/lo privado; lo masculino y lo femenino para construirse simplemente como identidad válida. En un análisis macrotextual más exhaustivo podrían retomarse nociones e instrumentos de la etnomusicología y el estudio de la recepción, a fin de completar este campo que en el artículo se trata solo de modo complementario.

Por último, me gustaría mencionar todos aquellos campos que quedan aún por explorar, como la recepción de "Lisístrata" mediante el estudio de los comentarios, la comparación entre la poesía de la autora y su rap, su vinculación con otros himnos feministas o su lugar en la propia producción de Gata Cattana, el estudio musicológico o performativo de la canción, etc.

En definitiva, los estudios del rap desde los ECD y la narratología feminista interseccional y queer son un vasto campo de análisis con múltiples enfoques para el trabajo con productos culturales. Además, el abanico de posibilidades que abre la integración de un discurso político con un formato estético no deja de sorprendernos en un mundo en constante cambio. Esto permite que una canción como "Lisístrata" introduzca al rap feminista como espacio legítimo de denuncia al mismo tiempo que resignifica y crea un subgénero novedoso en la propia escena del hip hop. El rap político de Gata Cattana como discurso con fuerza capaz de interpelar a una generación joven es precisamente lo que necesitamos para desmontar el discurso tradicional que oprime a los individuos por su comportamiento o idiosincrasia. La mujer en el hip hop, enunciando desde su condición de género, de raza, de sexo y orientación hace del rap un instrumento necesario para empoderarse.

En particular, desde España, Gata Cattana proyecta para el mundo entero un manifiesto feminista con el que interpela a individuos más allá del cronotopo de su creación. De esta forma, convierte al rap en obra de arte y contribuye al mito de la Gata, como una de las grandes referentes del rap español.

\section{REFERENCIAS}

Arkana, Keny (2011). Marseille. En L'Esquisse 2 [CD]. París: Because music.

Cattana, Gata (2014). Tributo. [Grabada por VentanalRecords].

Cattana, Gata (2015). Lisístrata. [Grabada por Wiloo]. En Anclas [EP]. Madrid: La cucaracha estudios.

Cattana, Gata (2017). Banzai [CD]. Madrid: D.Unison.

Collins P. y Birge S. (2019). Interseccionalidad e identidad. En Interseccionalidad,(pp. 113-133). Madrid: Morata.

Despentes, V. (2006) King Kong Théorie. París: Editions Grasset et Fasquelle.

Dijk, T. Van (2011). Sociedad y discurso. Barcelona: Gedisa.

Frith, S. (2001). Hacia una estética de la música popular. En Cruces Villalobos, F. (coord.) Las culturas musicales: lecturas de etnomusicologia, (pp. 413-436). España: Editorial Trotta.

Halberstam, J. (1998) Female Masculinity. Barcelona-Madrid: Egales.

Lane, Rebeca (2014). Mujer lunar. [Grabado por Armas, Julio]. En Canto. Guatemala: Mi Cuarto Estudios (producción independiente). 
Lanser, S.S. (1992). Fictions of Authority: Women Writers and Narrative Voice. Nueva York: Cornell University Press. Lanser, S. y Warhol W. (2015). Narrative Theory Unbound: Queer and Feminist Interventions. Columbus: Ohio State University Press.

Lanser, S. (2018). Queerring narrative voice. Textual practice, 32(6), 912-937.

Mafalda y Rebeca Lane (2018). Las que faltaron [Grabada por Laguna, A. y Boneet, J.]. RL Studios.

Martínez Vizcarrondo, D.E. (2011). Estrategias lingüísticas empleadas por los raperos/reguetoneros puertorriqueños. Enunciación, 16(2), 31-47.

Pardo Abril, N. G. (2012). Análisis crítico del discurso: Conceptualización y desarrollo. Cuadernos de lingüistica bispánica, (19) 41-62.

Spivak, G.C. (1993). Can the subaltern speak? En Chrisman, L.y Williams P. (Ed.), Colonial discourse andpost-colonial theory: a reader, (pp. 66-111). Birmingham: Harvester Wheatsheaf.

Tertuliano, Quinto Septimio Florente (s.f.) De cultu feminarum. 1.1. (s.d)

Tijoux, Ana (2014). Antipatriarca. En Vengo [CD]. Los Ángeles: National Records

Vila, P. (1996). Identidades narrativas y música: una primera propuesta para entender sus relaciones. Trans: Transcultural Music Review, 2. DOI: http://www.sibetrans.com/trans/articulo/288/identidades-narrativas-ymusica-una-primera-propuesta-para-entender-sus-relaciones.

\title{
Apéndice. Transcripción de la canción "Lisístrata", de Gata Cattana
}

\author{
Yo no camelo perfumes de Nina Ricci, \\ Soy más de libros de la Silvia Federici, \\ Será mejor que trates mejor a esas bitches, \\ No sea que de repente me escuchen y se compinchen. \\ Os lo tengo dicho, os lo dejo hecho, \\ Alpunto, La Teoria King Kong, ¿no? Apunta. \\ Facilito, tronco, deja de poner impedimentos, \\ Deja de ser un experimento. \\ Déjame ser otra cosa que no sea un cuerpo. \\ Deja de follarme con los ojos ya de paso, \\ cuando paso por la calle sola en todo momento, \\ porque me cago en to'o. \\ Yo, en pleno siglo XXI, ique tenga que venir la Ana a rebatir a Freud! \\ La tradición es larga desde Nietsche hasta Unamuno, \\ De Aristóteles a Darwin, desde Franco hasta Rajoy. \\ De aquellos barros a estos lodos, sépor dónde voy \\ Que las cosas no han cambia'o demasia'o a día de hoy. \\ Haciendo make it rain a lo Hard Candy, \\ Modus operandi, rayaos, estampa'os, rollo punky.
}

(Interludio: Eres la puerta del demonio (scratch), eres la que quebró el sello de aquel árbol prohibido, eres la primera desertora de la ley di (scratch)vina, eres la que convenció a aquel a quien el diablo no fue suficiente para atacar. Así de fácil destruiste la imagen de Dios y del hombre. A causa de tu deserción, mujer)

Que venga Dios y lo vea como a Gea se la marginó, Ardió en la hoguera con tres brujas durante la Inquisición. ¡Vale! que monten sus ministros festivales feministas 
Susana Pinilla Alba. Identidad y disidencia Sexual en el rap feminista Queer: un anÁlisis narrato...

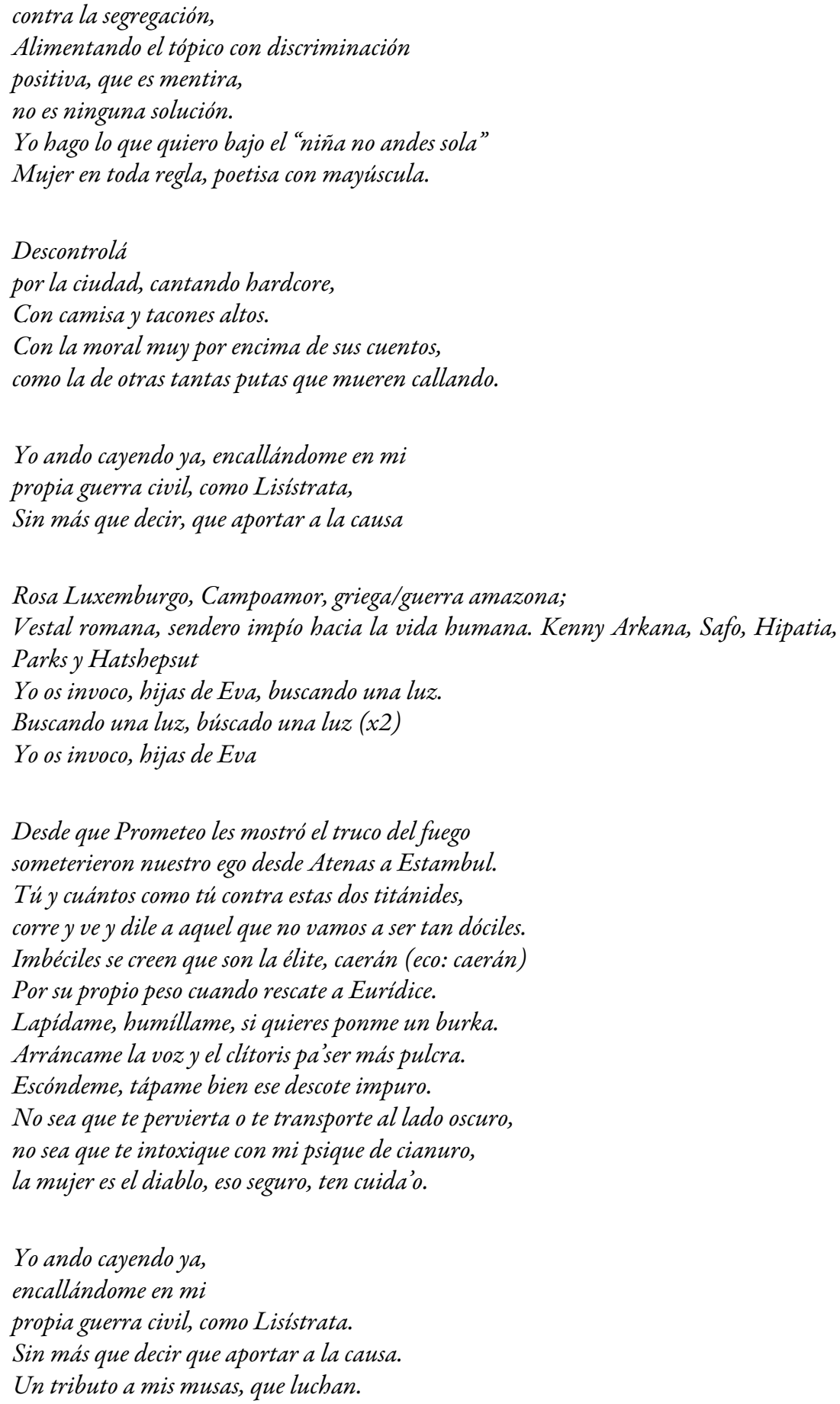

Interludio: Entiendo que la mujer, si no es prostituta, es tonta. Pero si no es ninguna de las dos, lo que sí está seguro es que es mala. Las mujeres no somos ni malévolas, ni malignas, no engendramos al demonio ni tampoco somos santas o que nos santificamos cuando llegamos a ser madres. Las mujeres somos mujeres.

\section{Notas}

1 Para ver el discurso completo, URL: https://www.youtube.com/watch?v=TIqGt8wGt24 y su transcripción: https://es.scribd.com/document/100029361/Intervencion-de-la-Asambleista-Rosana-Alvarado-conti nuacion-de-la-Sesion-174-Transcripcion-del-discurso. 
2 Silvia Federici (1942, Parma, Italia) es una escritora, profesora y activista feminista perteneciente al movimiento marxista. Es autora de Calibán y la bruja. Mujeres, cuerpo y acumulación originaria y de Revolución en punto cero. Trabajo doméstico, reproducción y luchas feministas, en los que sostiene la estrategia del capitalismo para poder producir libremente en el exterior mediante la asignación del rol de ama de casa a la mujer, impediendo así que salga de la esfera privada. Su tesis se basa en cómo la remuneración del trabajo doméstico podría acabar con la servidumbre y explotación que las mujeres sufren en sus hogares.

3 Robert Ricci fundó Nina Ricci en 1932 como regalo a su madre Nina. En 1998 la firma Nina Ricci fue adquirida por la compañía de moda y perfumes Puig que continúa comercializando perfumes con su nombre (Puig, 2019).

4 Podemos entender este adjetivo como subgénero del rap, estilo emparentado con el gangsta rap. Pero como adjetivo podemos entenderlo en relación a su origen, característica musical ligada al punk rock, más duro, violento y rápido que el punk regular (Urban Dicctionary, URL: https://www.urbandictionary.com/define.php?term=hardcore\%20rap).

5 La expresión "make it rain" significa en hip hop: "When you're in da club with a stack, and you throw the money up in the air at the strippers. The effect is that it seems to be raining money" (Urban dictionary. URL: https://www.urband ictionary.com/define.php?term=make+it+rain). Dicha expresión se extendió en contextos del gangsta o hardcore rap sin su vinculación con la sala de striptease, simplemente como el acto de arrojar dinero (o papeles que simulen dinero) como símbolo de estatus. Es el significado que han empleado algunos grupos españoles de trap. El grupo más conocido que popularizó este recurso y construyó un álbum en torno a ello fue Fat Joe y Lil Wayne. En este videoclip aparece el término vinculado con dinero que "llueve" sobre mujeres semidesnudas que disfrutan con esa lluvia de billetes: URL: $h$ ttps://www.youtube.com/watch?v=4dPjONDN3ZI

6 Hard Candy (2005) fue la primera película de David Slade. La historia se centra en la venganza que una niña de 14 años (Ellen Page) acomete contra un hombre de 32 (Patrick Wilson), del que sospecha que es un pedófilo. Ganó dos premios: en el Festival de Cine Fantástico de Sitges, en 2005 como Mejor Película, Mejor Guión, Premio del Público y en British Independent Film Awards (BIFA) en 2006, nominada como Mejor Película internacional independiente (Consultado en IMDb español, URL: https://www.imdb.com/title/tt0424136/?ref_=fn_al_tt_2).

7 La obra de los teóricos queer europeos, conocida sin duda por Gata Cattana, ofrece una demarcación entre la posición de resistencia, en la que enuncian los individuos considerados abyectos, y el terreno normatizado, donde se desarrollan los mecanismos disciplinantes que intentan borrar la expresión identitaria del individuo para asimilarlo a una masa anónima. El sentido elitista del rap conecta con esta intención reaccionaria.

8 Rapera francesa y activista de ascendencia argentina. Perteneciente a la escena de Marsella, fundó el colectivo anticapitalista de hip hop La Rage du peuple. Es un icono del rap conciencia francés y un referente universal.

9 Se trató de la mujer de un militar que encabezó una huelga sexual entre mujeres de Atenas y Esparta (llamamiento a sororidad) para que los hombres cesen la guerra (búsqueda de la paz). Las mujeres toman la acrópolis (símbolo del poder) y los hombres se ven obligados a hacer las labores del hogar y renunciar a dormir con sus esposas, situación que no soportan mucho tiempo, por lo que se rinde y se instaura de nuevo la paz. Se ha considerado a Lisístrata una promotora del feminismo en tanto que logró la paz por medio de asociación con otras mujeres para vencer a los hombres. Pero no es realmente una obra feminista como la vemos hoy en día, ni es seguro que Aristófanes tuviera estos ideales, posiblemente solo quería llevar a escena las consecuencias de que el hombre no tuviera sexo y hacer humor sobre la banalidad de la guerra. De uno u otro modo, lo que hizo Lisístrata fue una forma de rebeldía de las pocas maneras que una mujer podía sublevarse en la Grecia clásica. La obra no es feminista en tanto que el régimen patriarcal vuelve a instaurarse pasado el conflicto, que finaliza porque el varón no soporta estar sin sexo, como aparece en la comedia, tenía "inflamada la ingle" (Martignone, 2009).

10 No es ocasional el empleo del verbo "compincharse", que implica una unión sospechosa "con malicia y picardía" (según la RAE). Así pues, una unión de mujeres enfadadas debería asustar al oponente.

11 Referencia al mito de "Orfeo y Eurídice", este era hijo del dios de la música y la musa de la poesía. Bajó al Hades para rescatar a su amada, Eurídice, que había muerto como consecuencia de una picadura de serpiente. Con su música le abrieron las puertas del Inframundo y logró convencer a los dioses para que le dejaran pasar y recuperar a Eurídice.

12 "La Diosa Gea es considerada por los griegos la Tierra Madre, la deidad femenina principal, de donde surgen todos los dioses y los primeros humanos." Su progenitor era el Caos, por lo que no tiene ascendencia. Es el primer poder creador, ser que todo lo crea.

13 Todavía tienen lugar fiestas para conmemorar el poder fructífero de la tierra en regiones de Perú y Ecuador, como vemos en esta noticia: "La fiesta en homenaje a la madre tierra que se la celebra desde hace ocho años en Zamora Chinchipe, bajo el nombre del 'Pachamama Raymi', fue presentada oficialmente ayer en una ceremonia que estuvo acompañada de rituales y exposición de diferentes productos" (Periódico digital La hora, 24.03.2018. Consultado el 04.11.2019: https://lahora.com.ec/zamora/noticia/1102144562/el-pachamama-raymi-una-de-las-fiestas-mas-grandes -del-sur-del-ecuador-).

14 Los primeros programas conformados con tales criterios se idearon a mediados del siglo XX en los Estados Unidos, momento en el que se empezaron a implementar una serie de medidas legales en favor de minorías tradicionalmente 
Susana Pinilla Alba. Identidad y disidencia Sexual en el rap feminista Queer: un anÁlisis narrato...

marginadas que recibieron el nombre de "acción positiva" (affirmative action), etiqueta que corresponde a lo que en otros lugares se conoce como "discriminación positiva" o "discriminación a la inversa". (Velasco Arroyo, 2007, p. 142)

15 Existen partidarios y detractores de este conjunto de leyes. "Hay así quienes alegan que defender políticas activas en favor de un determinado colectivo constituye una forma de paternalismo estatal avalado por la fuerza de la ley, pues, de alguna manera, determinados ciudadanos serían tratados como si fueran menores de edad. Es más, tales medidas se situarían en abierta contradicción con el precepto antiperfeccionista liberal. Para quienes se muestran partidarios de una sociedad regida por el mérito personal como máximo criterio de justicia, la inadecuación de la discriminación positiva no podría ser mayor. En esta dirección, una objeción tópica es la formulada por Giovanni Sartori (2003, p. 51) con total sencillez y contundencia: 'La discriminación consiste en favorecer o desfavorecer injustamente a grupos de personas basándose en cuestiones que son ajenas a sus méritos y habilidades' (Velasco Arroyo, 2007, p. 148)”.

\section{BY-NC-SA}

